\title{
Implementation of Electronic Human Resource Management
}

\author{
S.K. Manivannan, M. Valliammal
}

\begin{abstract}
While the HR has to play a strategic role in company, the HR professionals are burdened with administrative work ranging from $36 \%$ to $50 \%$ of the total HR function effort (Mercer, 2013). However it is known that Information Technology projects have a high rate of failure and so is EHRM. Hence a study of the indicators for success and factors that determine success of E-HRM is needed to guide HR function for better results.

This research had used new Technology Acceptance Models to study the implementation aspects of EHRM that can result in success in EHRM projects using an Multinational Automobile major as a case study. The aspects of implementation success factors included "Function", "Output", "Subjective Norm", "Result Demonstrability" and "Perceived Ease of Use".
\end{abstract}

Index Terms: EHRM, HRIS.

\section{INTRODUCTION AND MOTIVATION FOR RESEARCH}

As per Lepak \& Snell (1998) HR function helps the organization in developing core competencies. Lawler \& Mohrman (2003) opine that HR's greatest opportunity is in development of corporate strategy and implementations of same, enabling the organization develop the needed capabilities. HR function should develop human capital to execute the firm's business strategies (Alvares, 1997). To help HR in that e-HRM is a great tool to reduce the routine effort of HR.

\section{Motivation for the Study}

A key strategy to reduce the time spent by HR function on administrative work is to embrace automation of HR function using E-HRM (Lepak \& Snell, 1998). As the time required for strategic contribution of HR function will keep increasing while the requirement of efficiency will demand a negative pressure on recruiting any additional resources, the main alternative available for $\mathrm{HR}$ function to balance the conflicting interests will be to either automate or outsource the essential but less value adding functions (Mercer, 2013).

As E-HRM is the key method for automating HR functions it is essential that a focus on its successful implementation is needed to reap the benefits. However it is known that Information Technology projects have a high rate of failure, anywhere from $30 \%$ to $80 \%$ (Manchanda et.al., 2013). Being an IT initiative, E-HRM implementation is also susceptible for failures during implementation. Hence a study of the indicators for success and factors that determine success of

Revised Manuscript Received on July 05, 2019.

Dr. S.K. Manivannan, Faculty Member, School of Management, SRMIST, Kattankulathur, Tamizhnadu, India.

Dr. M. Valliammal, Faculty Member, Dept. of Management Studies, SRMIST, Vadapalani, Tamizhnadu, India.
E-HRM is needed to guide HR function for better results.

\section{Research Gap}

Research work in the field of Implementation of Human Resource Automation is very limited in Indian industry, and even less in the area of Electronic Human Resource Management (E-HRM). There are no researches done to explore the differences in factors influencing successful implementation of E-HRM at Manufacturing and IT firms. With this background, the general objective of the present research is focused on Comparative Analysis of Implementation of E-HRM in IT and Manufacturing firms in Chennai.

\section{STATEMENT OF THE PROBLEM}

There is an urgent need to embrace automation of HR function to take up more value adding tasks for $\mathrm{HR}$. At the same time we find that more than $80 \%$ of the IT system implementations fail. Therefore we need to identify the criteria for success as well as factors leading to success of E-HRM projects. This research is focused on addressing this problem by a study of 'Implementation of electronic human resource management using a comparative analysis of it firms and manufacturing firms in Chennai.

\section{REVIEW OF LITERATURE}

Studies on E-HRM Implementation in Indian firms are limited. The literature so far reviewed relates to the studies conducted outside India and very few studies were conducted in Indian firms in Information Systems Implementation. A brief of the studies on IT system implementation success are mentioned below which may throw light on the E-HRM implementation.

\section{Technology Acceptance Models}

A fair amount of research into IT acceptance has been done in the past, which can be used to see how E-HRM acceptance can be determined. User acceptance theories like Technology acceptance Model (TAM-Davis, 1986), Taylor's Theory of Planned Behavior (Taylor \& Todd, 1995) are used to explain IT acceptance. Acceptance of IT by User measured as the usage intention or actual IT use, is these models' basic concept.

Further Venkatesh et al. (2003) formulated and validated Unified Theory of Acceptance and Use of Technology (UTAUT) consolidating eight user acceptance models and using four main constructs required for system usage, namely, effort expectancy (the ease of using technology), performance expectancy

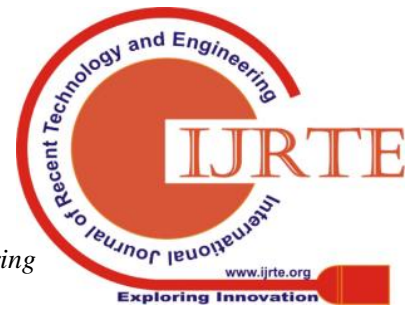


(technology usefulness), social influence (acting on individuals prodding technology usage) and other conditions that facilitates. Their research found most factors, to be related to an individual's intention to use a system.

But TAM and UTAUT models address only the User Acceptance of the system. Though user acceptance is crucial for E-HRM implementation success, use of this model alone may not suffice for the identification of factors enabling success in E-HRM implementation. Hence our search led us to the following model.

\section{Information System Success Model}

DeLone and McLean found Information System success as combination of six dimensions, which are given below (DeLone and McLean 1992):

1) Quality of System - is the measurement of the system processing information,

2) Quality of Information -is the measurement of output of the information system,

3) Actual Use - is the how the recipient consumes the output of an information system,

4) Satisfaction of User - is the response of recipient to the use of information system's output,

5) Impact on Individual -is the measurement of effect of information on the recipient's behaviour, and

6) Impact on Organization -is the measurement of effect of information on recipients' organizational performance.

\section{NEED FOR THE STUDY}

There is both practical and theoretical significance of conducting a research study of this nature. The potential for better implementation of E-HRM projects in the industry will not only ensure huge cost savings, but also ensure that the Indian industry and their employees can reap benefits of better Human Resource Management, especially in the current era where people are the biggest assets for firms.

The theoretical significance of this study is that there has been very little research on implementation of E-HRM conducted for business organizations especially in Indian firms. Thus, these results will also facilitate knowledge-based recommendations that can be employed to better meet the goals of successful implementation of E-HRM besides meeting expectations of the stakeholders.

\section{V.OBJECTIVES OF THE STUDY}

The primary objective of the present research is focused on "E-HRM Implementation and a Comparative Analysis of the implementation at IT and Manufacturing firms in Chennai.".

The secondary objectives of the study are:

To analyze factors that lead usage or intention to use E-HRM systems

To examine the factors affecting successful E-HRM implementation projects

I. To determine success indicators from which E-HRM success can be decided.

II. To evaluate the relationships between success factors and indicators

III. To evolve appropriate management strategies to ensure E-HRM implementation success

IV. To evaluate the relationships between success factors and indicators

V. To evolve appropriate management strategies to ensure E-HRM implementation success

\section{HYPOTHESIS OF THE STUDY}

The hypotheses to be tested are:

I. The factors, subjective norm, perceived usefulness and perceived ease of use do not significantly affect personnel to use or create the intention to use E-HRM systems.

II. The factors Intention to use/actual use, project progress and quality of E-HRM system do not affect success of E-HRM implementation.

III. The factors Intention to use/actual use, project progress and quality of E-HRM system are not significant indicators of success for E-HRM implementation.

IV. The E-HRM success indicators (Intention to use/actual use, project progress and quality of E-HRM system) do not have any significant relationships with the success factors, namely subjective norm, perceived usefulness and perceived ease of use.

V. There are no significant difference between manufacturing and IT firms in terms of the factors influencing E-HRM success

\section{RESEARCH METHODOLOGY \\ Scope of the Study}

The study finds the indicators of success of E-HRM based on previous research on IS implementation projects where user interactivity and managerial impact high, such as the ERP project implementation since literature on E-HRM implementation is scarce. Further the factors influencing the success of E-HRM are explored again from the past literature. Building a structural model the relationships between the success factors and the success indicators will be explored besides the inter-variable relationships as well. The model so evolved and the identified hypotheses will be tested using the data gathered from firms who have implemented E-HRM The firms are chosen to have a fair representation of both manufacturing and IT firms from Chennai. Among the different Industrial hubs in India, the Chennai city has been selected for the present study as we find adequate number of firms engaged in both lines of business.

\section{Methodology}

Based on an extensive review of literature success factors and success indicators were identified and the proposed relationship among them was modeled using a structured model. A structured questionnaire was developed to gather the data for validating the model and the hypotheses. A pilot survey was conducted contacting about 45 respondents in two firms, one in the manufacturing sector and other in IT to validate the reliability of the instrument and the items and based on the analysis the questionnaire was revised for the main study. Other findings from pilot survey are discussed later in findings

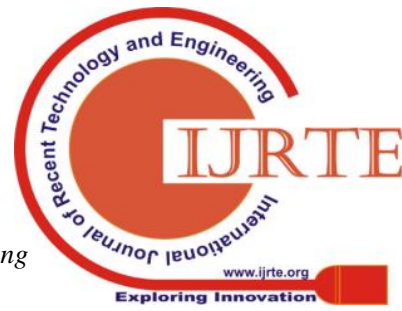


section.

Data Collection: A list of firms in Chennai was collected from appropriate sources and having shortlisted those who had implemented E-HRM, those companies were classified into Manufacturing and IT firms. The Manufacturing firms namely Chennai Petrochemicals, Ford, TI Cycles and Rane India and the IT firms namely HCL and Wipro are randomly selected from the list. Totally 281 employees are again randomly selected for the present study by adopting stratified random sampling technique from these companies and their responses gathered through pre-tested, structured interview schedule by direct interview method. The data and information collected from respondents pertains to the year 2014. Of these 263 were valid responses.

Analysis: The factors were found using factor analysis. Samples comparison done using ' $t$ ' tests or analysis of variance. Regression analysis examined the relationships of indicators to factors.

A Structural Equation Modeling (SEM) was done to check model validity by comparison with regression model. the E-HRM software the respondent's company currently uses.

\section{Research Model}

The study used the following model to depict the variables studied and the proposed relationship based on the hypotheses. The variables and the constructs have been described further in the appendix in this document.

\section{Summary of Data Analysis}

Items for the variables "consultant support" had low response rate. Items for organizational impact that had cost savings and revenue increases also have relatively low response rate $(81 \%, 79 \%$ respectively). As respondents can guess whether or not such benefits from the E-HRM system exist, but not assess these benefits for the organization exactly, making some respondents reluctant to answer these questions.

\section{MAJOR FINDINGS AND CONTRIBUTIONS}

Surveyed over 300 and received 281 responses, with 263 valid responses. The main survey included a question about

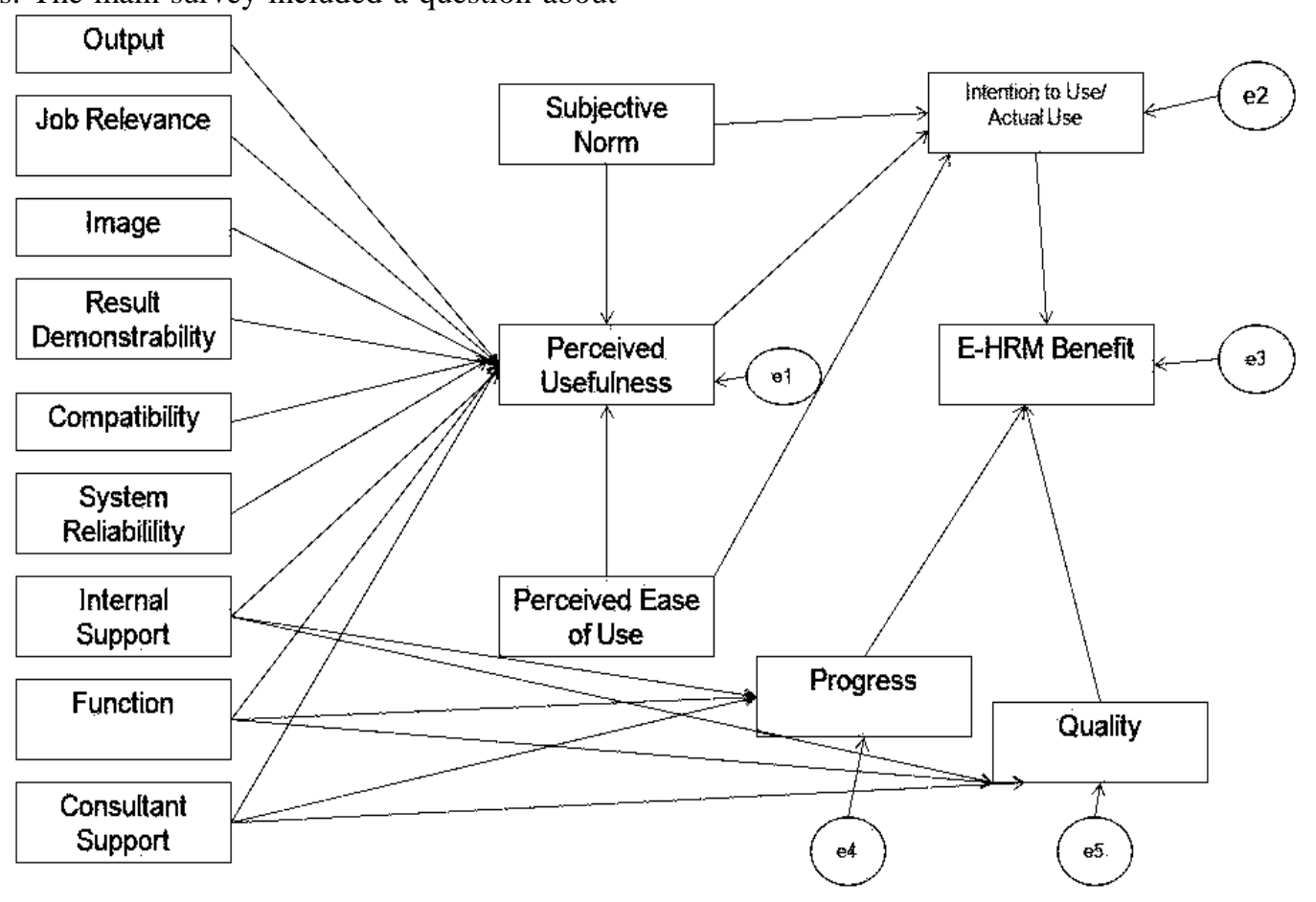

Table 1. Analysis with Structural Equation Modeling Goodness of Fit Indices for the Measurement Model

\begin{tabular}{|c|c|c|c|}
\hline $\begin{array}{c}\text { Goodness } \\
\text { of Fit } \\
\text { Indices }\end{array}$ & $\begin{array}{c}\text { Original } \\
\text { Model }\end{array}$ & $\begin{array}{c}\text { Revised } \\
\text { Model }\end{array}$ & $\begin{array}{c}\text { Desired } \\
\text { Levels }\end{array}$ \\
\hline$\chi^{2 / \mathrm{df}}$ & 292.19 & 114.25 & Smaller \\
\hline $\mathrm{df}$ & 42 & 45 & - \\
\hline$\chi 2 / \mathrm{df}$ & 6.96 & 2.54 & $<3.0$ \\
\hline RMSEA & .15 & .07 & $.05-.08$ \\
\hline NFI & .89 & .96 & $>.90$ \\
\hline CFI & .90 & .97 & $>.90$ \\
\hline TLI & .66 & .91 & $>.90$ \\
\hline
\end{tabular}

The first main analysis done in this research was a comparison of samples using $\mathrm{t}$ tests or analysis of variance (ANOVA). Four comparisons in terms of respondents' industry, software, years of experience, and use hours were done. Then regression analysis to examine the relationships between factors and indicators was conducted. To identify relationships between factors and five different dependent variable attributed to E-HRM success; five different regression models were presented. The research found that significant differences exist between the manufacturing and IT samples by way of regression analysis.

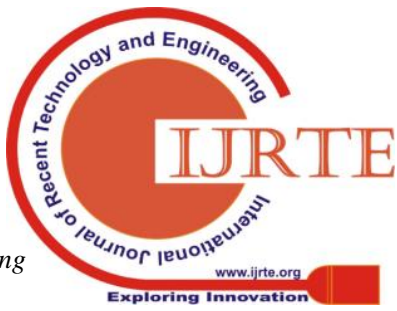


The Structural Equation Modeling (SEM) analysis show no difference of SEM and regression analysis. The alternative "Best Fit Model" has better goodness of fit indices and a better parsimony.

Common Method Variance was tested with Harman's single factor and found that there was impact on the correlations among the variables and factors.

\section{Implications for Successful E-HRM Implementations}

If E-HRM system succeds, the more the benefits to company. Purpose is to increase business value to increase efficiency and eliminate waste. This study identifies that "Intention to Use / Actual Use" and "Quality" as main determinants of "E-HRM Benefits". Further E-HRM system stakeholders should consider the factors affecting usefulness, leading to E-HRM success. Recommendations to improve usefulness are:

1) The well defined functions of the E-HRM system.

2) Encourage all employees to use of E-HRM system for business value.

3) Make quality of system output a priority particularly with reports.

4) Make E-HRM system user friendly.

5) Clearly define the goals and communicate to all.

\section{Limitations}

Though the research made all effort to identify the factors that affect EHRM success based on the comprehensive review of literature and interviews with industry experts, there could be a chance that more factors meriting serious consideration exist. Since there are a lot of reasons that lead to success or failure of EHRM systems and as these may differ from case to case, it will be difficult to consider all the possible factors associated with EHRM success. However using all the factors can negatively impact the parsimony of the proposed model. Still the revised model has achieved an RMSEA score of 0.07 suggesting that the data has a good fit for the revised model with good parsimony.

\section{SUGGESTIONS AND CONCLUSION}

The present study indicates that top management needs to play a stronger role than currently evidenced in the organizations taken up as samples. The role to be played includes defining a clear goal of implementation and the criteria for successful implementation, preferably attaching quantitative metrics such as increase in productivity or reduction in cost etc. The communication of these goals to entire organization also should be the most important responsibility of the top management. This communication has to be clear, outlines the expected goals, impact in terms of individual roles as well training and top management commitment to achieve the goal come what may.

The present study indicates that the Manufacturing and IT firms differ in terms of the employee's expectation from E-HRM and subsequently the factors affecting success of E-HRM implementation. The key finding in this study is that success in E-HRM implementation depends on the factors the organization definitely has a control on during the planning and implementation phases for the system.
At the planning stage the management has to judiciously formulate the objective of implementing such a system, select capable leadership and guidance so as to evolve a system that has the needed functionality to achieve the objectives, meticulously maintain the quality of implementation and usability of the system.

This study also stresses the need to monitor company culture and encourage the best practitioners in using the system to ensure that employees' organizational commitment is maintained at high levels during implementation.

This study also reveals that success of the E-HRM implementation is positively related to the external consultants who play an important role, in case the firm has no prior experience in implementing IT systems. Hence firms who are planning to go for automating HRM, will need an able mentor who can handhold them during implementation. This aspect is very important for manufacturing firms than IT firms.

However, the findings also indicate the importance of ensuring the usage by various means. System that has been implemented will not be complete unless it is used and the organization derives benefit out of it. Making sure through multiple means that the system is used will go a long way in making the project successful. Here also the management must provide the directional and cultural impetus for such push of the system usage. This aspect is also more important for manufacturing firms than IT firms.

Providing employees with proper training and development saves time and enables employees to do the correct thing right the first time, thereby increasing their job satisfaction, efficiency productivity and ultimately, their commitment to improvement through the system.

In conclusion, organizations should plan the implementation with a long term plan in mind and not just for a short term tactical reasons. The involvement of top management in terms of clear goals, communications to all stakeholders and check the progress periodically are essential to ensure success of E-HRM project.

\section{REFERENCES}

1. Alvares, K. M. (1997). The business of human resources. Human Resource Management, 36(1), pp.9-15.

2. DeLone, W.H., McLean, E.R., 1992. Information Systems Success: The Quest for the Dependent Variable. Information Systems Research 3 (1), 60-95.

3. Davis, F.D., R.P. Bagozzi \& P.R. Warshaw (1989), User acceptance of computer

technology: A comparison of two theoretical models, Management Science, Vol.

35, No. 8, pp. 982-1003

4. Lepak, D.PP. \& S.A. Snell (2002), Examining the Human Resource Architecture: The relationships among human capital, 
employment, and human resource

Configurations, Journal of Management, Vol. 28, No. 4, pp. 517-543

5. Manchanda, D., Singh, A., \& Garg, N. (2013). An Insight upon the Effect of Quality Assurance on the Cost of Software Development. International Journal of Computer Applications, 80(13), 4-10.

6. Strohmeier, S. (2007). Research in e-HRM: Review and implications. Human Resource Management Review. 17(1),19-37

7. Ulrich, D. (1997), Human Resource Champions; The next agenda for adding value and delivering results, Harvard Business School Press

8. Ulrich, D. (1998), A new mandate for Human Resources, Harvard Business Review, Vol. 76, No. 1, pp. 124-134

9. Venkatesh, V., M.G. Morris, G.B. Davis \& F.D. Davis (2003), User Acceptance of Information Technology: Toward a Unified View, MIS Quarterly, Vol. 27, Nr.3, pp.425-478

10. WMFC (1999), Workflow Management Coalition Terminology \& Glossary, The Workflow Management Coalition Specification, No. 3

11. Wright, P.M. \& G.C. McMahan (1992), Theoretical perspective for Strategic Human Resource Management, Journal of management, Vol. 18, No. 2, pp. 295-320

12. Youndt, M.A., S.A. Snell, J.W. Dean \& D.P. Lepak (1996), Human resource management, manufacturing strategy, and firm performance, Academy of Management Journal, Vol. 39, No. 4, pp. 836-866 